\title{
CONCURRENT ENGINEERING APPROACH IN DESIGN OF TEST EQUIPMENT FOR DETECTING FARM TRACTOR MECHANICAL PERFORMANCES: APPLICATION TO DEVELOPMENT OF HUB-ADAPTER
}

\author{
Marco Bietresato, Francesco Selmo, Fabrizio Mazzetto \\ Libera Universita di Bolzano, Italy \\ marco.bietresato@unibz.it
}

\begin{abstract}
The development of a test system to complete existing equipment in a research laboratory is a real design-activity, with even high complexity levels and many constraints, in terms of resistance to mechanical stresses and geometric connectivity to existing mechanical interfaces as well. Such a project must also be focussed, if possible, on cost saving and realisation speed, to make the best possible use of research funds, having often a limited time-availability. Concurrent Engineering (CE), born in the early 90s, is as a well-defined system approach to optimize the design and engineering cycles, with emphasis on tasks parallelization. In particular, CE revolves around the concept of considering all elements of a product lifecycle in the early design phases. By doing so, the resulting project is virtually free from design errors, which are expensive to be corrected in existing components and critical for the success of that project. The "Theory of Inventive Problem Solving" or TRIZ includes a practical methodology, some tools, a knowledge-base and a model-based technology for generating innovative solutions for problem solving. CE and TRIZ together can be particularly-effective also in the design of unique components, e.g. those composing the equipment of a research laboratory. This work illustrates the approach followed in defining a component of a system to measure the agricultural machinery performance. This rig will connect the rear wheels of a tractor to an existing PTO-dyno through two multiplication stages. In particular, the cited methodologies have been applied in the development of a hubadapter, i.e. the element that interfaces with the machine in test. The research for technical documentation and standards, the direct measurement of existing parts, the computer-aided design with 3D-modelling and finite element calculation of the components, have allowed to obtain iteratively a project verified in all aspects, ready to be realized.
\end{abstract}

Keywords: agricultural machines; engine performance; PTO-dyno; Concurrent Engineering, TRIZ.

\section{Introduction}

\subsection{Background}

The topics of energy efficiency and pollution control nowadays involve all production sectors, including agriculture and agricultural machinery, which is therefore not exempt from the need for innovation [1;2], as well-known by scholars belonging to research groups in Agricultural Engineering. At the Agroforestry Innovation Lab of the Free University of Bozen-Bolzano there are many projects [3] aimed at this direction. An example is the "BIO-TRACT-EFFICIENCY" project, whose aim is to analyse several aspects related to the operation and efficiency of the whole powertrain (engine + transmission) of agricultural machines, also when they are powered by alternative fuels. The analysis of the tractor system requires a rig that can measure the quantities of interest (i.e. the mechanical outputs of tractors), and for this reason, the initial phase of the project is dedicated to the development and construction of specific equipment. In particular, the test equipment underdevelopment will be used to measure the performance of an agricultural machine at the wheels (i.e. the torque and power actually available to the user as a function of the wheels rotational speed), hence in conditions similar to those experimented by a tractor in the field or on the road. The starting point is a PTO-dyno already owned by the university (a "SIGMA 50 Mobile" PTO-dyno by N. J. Froment \& Co Ltd, Easton-on-the-Hill, East Northamptonshire, England, UK; [4]), useful to apply a breaking torque to the engine. This device is designed to be connected to the tractor PTO (in terms of operative range and mechanical interfaces) to measure the engine output upstream of the transmission, exploiting the direct connection between the engine and PTO [5-10]. It is therefore necessary to create a mechanical connection between the tractor propulsion elements and the PTO-dyno. By limiting the vehicles of possible interest to wheeled tractors, it was therefore decided to develop a rig able to be connected to the rear wheels, which are always involved in traction (even in 4WD tractors). Therefore, the objective of the project is to develop a compact low-cost system (about 30000 EUR) making use of the PTO-dyno already available. This means that there is the need to conceptualize, design and build such a system, with the additional difficulty that there is no possibility to create any prototype to 
be iteratively modified, due to budget limitations. Especially in cases like this one, it is therefore advisable to adopt an advanced design philosophy such as the "Concurrent Engineering" (CE). It is an integrated design process that takes into account all aspects of concept, development, manufacturing, assembly, end-of-life, maintenance, reliability and many others [11-15]. Thanks to its conceptual approaches of the "Design for Manufacturing" and "Design for Assembly" (DFM, DFA, together: DFMA), CE allows to anticipate, already at the design phase, all the possible issues typical of the subsequent product-development phases (specifically, of the manufacturing and assembly phases respectively for the DFM and DFA [16; 17]). Therefore, CE allows having an overall view of a project since the early stages of its development in order to minimise subsequent changes, which usually lead to errors, increased costs and time losses. Synergy, simultaneity and foresight are therefore the keywords in the application of CE techniques. In addition, it is advisable to support the design effort by also using a methodology that guides the designer's creativity, namely the "Theory for Inventive Problem Solving" or TRIZ. This is based on abstraction and generalization of a specific design problem to find a specific solution from a general solution and gives very practical tools to reach this scope [18-20].

\subsection{Aim of this work}

Many of the above-cited CE methods are well-established design procedures when they are used singularly, but very little examples show their joint application, especially to the design of experimental installations. So, the aim of this work is demonstrating the effectiveness of these design methods in the development of a test rig, like the one described here, thus letting other designers face similar situations and design issues. At this purpose, a single component of this rig has been used as an exemplifying case-study: the hub-adapter to be used to connect each rear axle shaft of a tractor to a sprocket, which is the first component of the test rig (Fig. 2). Hence, the effectiveness of CE methods has been shown by describing: (1) the reasoning that has lead the evolution of the adapter design through four subsequent versions and (2) the techniques/design principles used to define each version, underlining the changes that these techniques have progressively brought to the project.

\section{Materials and methods}

The design of a novel test rig can be even very complex, so the designer can need some advanced design techniques to aid him. As exposed before, all the lifecycle aspects of the adapter have been analysed and specific product-features have been developed by adopting a CE approach. The methods belonging to $\mathrm{CE}$ drive the designer along well-organised algorithmic design-paths, and also allow him expanding his capabilities, by tackling the problem from many different and new points of view. In the proposed case, two of the most important aspects to consider in the development of the hub-adapter are: avoiding any manufacturing issue and ensuring the connectivity during the assembly phase. The evaluation of these aspects cannot be entirely delegated to producers or assemblers, not to delay the realization or compromise the usability of the developed product. For the explained reasons, it was decided to adopt the DFMA methodology. Indeed, it offers many conceptual tools, such as: design procedure guidelines, material-and-process selection tables, optimization guidelines, optimality evaluation parameters, common solutions for product simplification, etc. Other issues to be faced while designing a completely-new product, like this adapter, are mainly related to the designer's creativity/invention: completely-new features must be thought, and some design problems must be solved creatively. The TRIZ methodology offers powerful and practical tools to deal with these aspects, e.g. the "table of contradictions" and the "table of inventive principles", applied specifically in the present case.

\subsection{Main guidelines for practical implementation of $\mathbf{C E}$}

The implementation of CE implies the simultaneous use of as many virtual prototyping tools, design methodologies [21] and problem-solving strategies as possible. Specifically, the following list reports the tools, methodologies and strategies used for the design of the adapter:

- extensive use of mechanical engineering software for the design, visualization, dimensioning and simulation of the system under development, to help the designer find many errors at an early stage and refine iteratively the project; in this case, the CAD program used is Solidworks 
2018 (by Dassault Systèmes, Vélizy-Villacoublay, France [22]), whilst Solidworks Simulation 2018 (part of Solidworks) and Ansys 2019 R2 (by Ansys Inc., Canonsburg, Commonwealth of Pennsylvania, USA [23]) were used for FEM structural calculations; KISSsoft 2019 (by KISSsoft AG, Bubikon, Switzerland) has also been used for the design of cogwheels and the calculation of transmission stages;

- use, as much as possible, of consumer/standardized components that are already available on the market, including used components, possibly previously-designed for other purposes (i.e. considering also a change of use) and use of state-of-the-art equipment for the size measuring and reverse engineering of already-available components (i.e. a structured-light 3D scanner); for this reason, it was decided to interface with various industrial suppliers, so as to be aware of all the possible alternatives and costs for many parts of the system under development;

- use, as much as possible, of standardized dimensions (as indicated in international standards and mechanical design manuals)for the components to be manufactured, therefore enhancing the ease of manufacturing; moreover, if the use of these standardized components is consistent with their intended purpose, their resistance is also guaranteed;

- direct interfacing with the companies that have to manufacture and assemble the components, and with the operators that have to use the resulting equipment, respectively to be aware of the machines and manufacturing procedures that will be used and to meet the manufacturing/assembling/operating possible problems.

\subsection{Enumeration of design requirements for the definition of the system features}

To better define the features that a system should have, it is necessary to make explicit, already in the concept phase, the design requirements (divided in four groups; see Fig. 1) referred to the whole product-design cycle, whether they are mandatory (binding) or optional (preferential):

- Technical-structural requirements; they concern everything that is related to the static and dynamic dimensioning and kinematics of the system, its shape, its overall and detail dimensions, its compatibility/interchangeability and its fixing subsystems;

- Manufacturing requirements; they concern everything that is related to the choice of materials, fabrication processes, transport, including also the costs;

- Operation and user-related requirements; they concern everything that is related to the system assembly/installation and disassembly, its operation and the possibility to store it when inactive, the possibility to use already-available tools and instruments, the skills to be owned by technicians having to deal with it;

- Safety requirements; although these requirements are closely-interconnected with the other categories (in particular to the previous category), they deserve to be a separate group, to give them a greater importance; they concern everything that is related to handling (e.g., weight, presence of sharp edges and hooks/handles), the presence of physical barriers around the power/energy sources (e.g., motion, heat, electricity, noise, vibrations) and the containment of toxic chemicals.

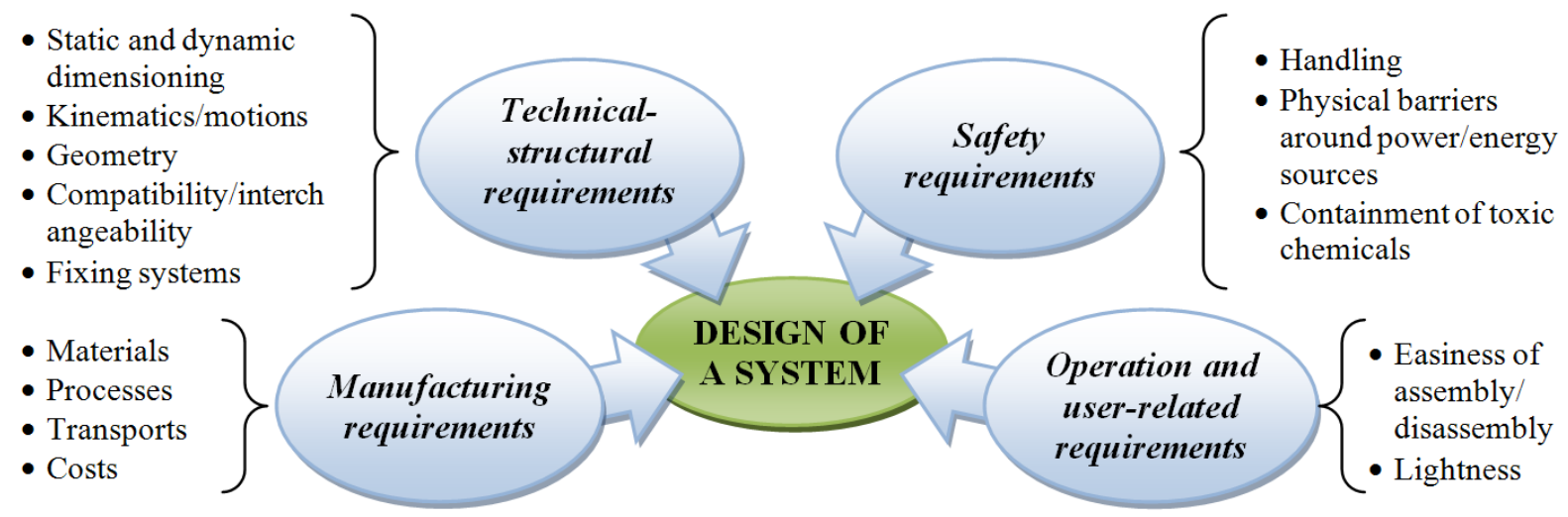

Fig. 1. Definition of the system features through enumeration of the design requirements 


\section{Results and discussion}

\subsection{Definition of the engineering macro-problem}

There is the need to connect a single-strand B-type sprocket (i.e. a sprocket with a hub that extrudes on one side), which is the first transmission stage of the test rig for tractors (not object of this study), to each rear axle shaft of the tractor to be tested (precisely, to its wheel hubs). The sprockets have a diameter of $1.25 \mathrm{~m}$ and will replace the rear wheels of the tractor (Fig. 2), so it is possible (and advisable) to use the same bolts normally used to fix the rims, already dimensioned (in terms of diameter and position) to transmit the torque of the tractor. The coupling system of the rim with the axle shaft has not the same characteristics (in terms of typical dimensions, bolts) for all tractors, but varies mainly according to the size/nominal power of the machine itself. Indeed, the rim diameter increases typically as the power of the tractors increases, and the coupling systems are also adapted accordingly. International standards divide the rims into 8 dimensional classes, each characterised essentially by different values of four main parameters parametrized to the rim disc diameter [24;25]: the pitch circle diameter, the bolt hole diameter and number, the central bore diameter (Fig. 3). It is therefore desirable (and necessary to limit the costs) to design a "universal" connection system that can connect to the hubs of the two wheels without necessarily having a different pair of sprockets per each dimensional class within a set threshold of nominal power. A preliminary study on a tractor database, representative of the Italian tractor pool, showed that $70 \%$ of the orchard/vineyard tractor market uses only 2 classes of rims, thus simplifying a lot this problem [26; 27].

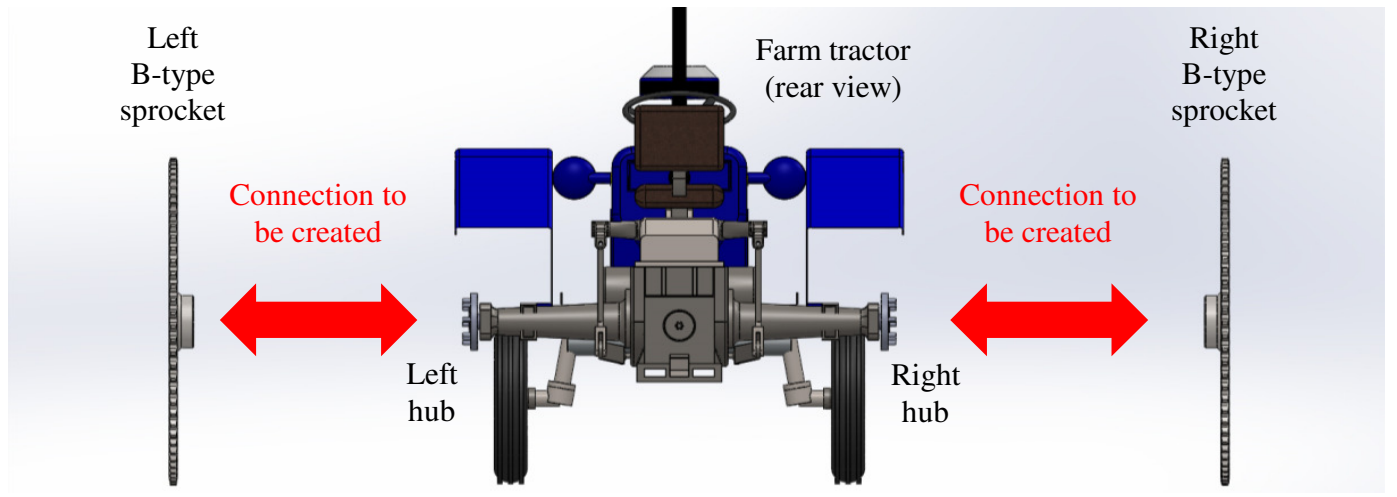

Fig. 2. Macro-problem layout



Fig. 3. Wheel-to-hub fixing dimensions from ISO 5711 Standard (A) and example of fastening system on the tractor axle shaft hub $(B)$ : $D_{1}$ - pitch circle diameter; $D_{2}-$ stud hole diameter; $\mathrm{D}_{3}$ - central bore diameter; $\mathrm{D}_{4}$ - disc flat bearing diameter; $\mathrm{D}_{5}$ - centring diameter on the hub;

$\mathrm{D}_{6}$ - diameter of the hub flat bearing) 


\subsection{Definition of the system configuration thanks to TRIZ and DFMA}

To solve the above-illustrated situation, the TRIZ inventive principles [28] were used to proceed (Fig. 4.A). Specifically, the principles that guided this decision are: number 1 "Segmentation / Division" and number 24 "Intermediary / Intermediate means" (Fig. 4.B). Thanks to these principles and to the many examples that are reported in the literature about TRIZ, it was thought to develop an "intermediate adapter" (i.e. a proper connection system, hereinafter referred to simply as "adapter") to be used between each sprocket and the corresponding axle shaft. The use of these adapters allows connecting standard sprockets to various types of tractors, each of them with a different class of wheel-to-hub connections. The advantages of developing such a system are considerable and solve the problem of having many types of sprockets. Once the type of the connection system has been macroscopically defined in its concept, the system requirements to guide the design phase of the adapter (in terms of design constraints, suggestions and/or manufacturing methods) are hence defined according to CE [31] (Table 1).

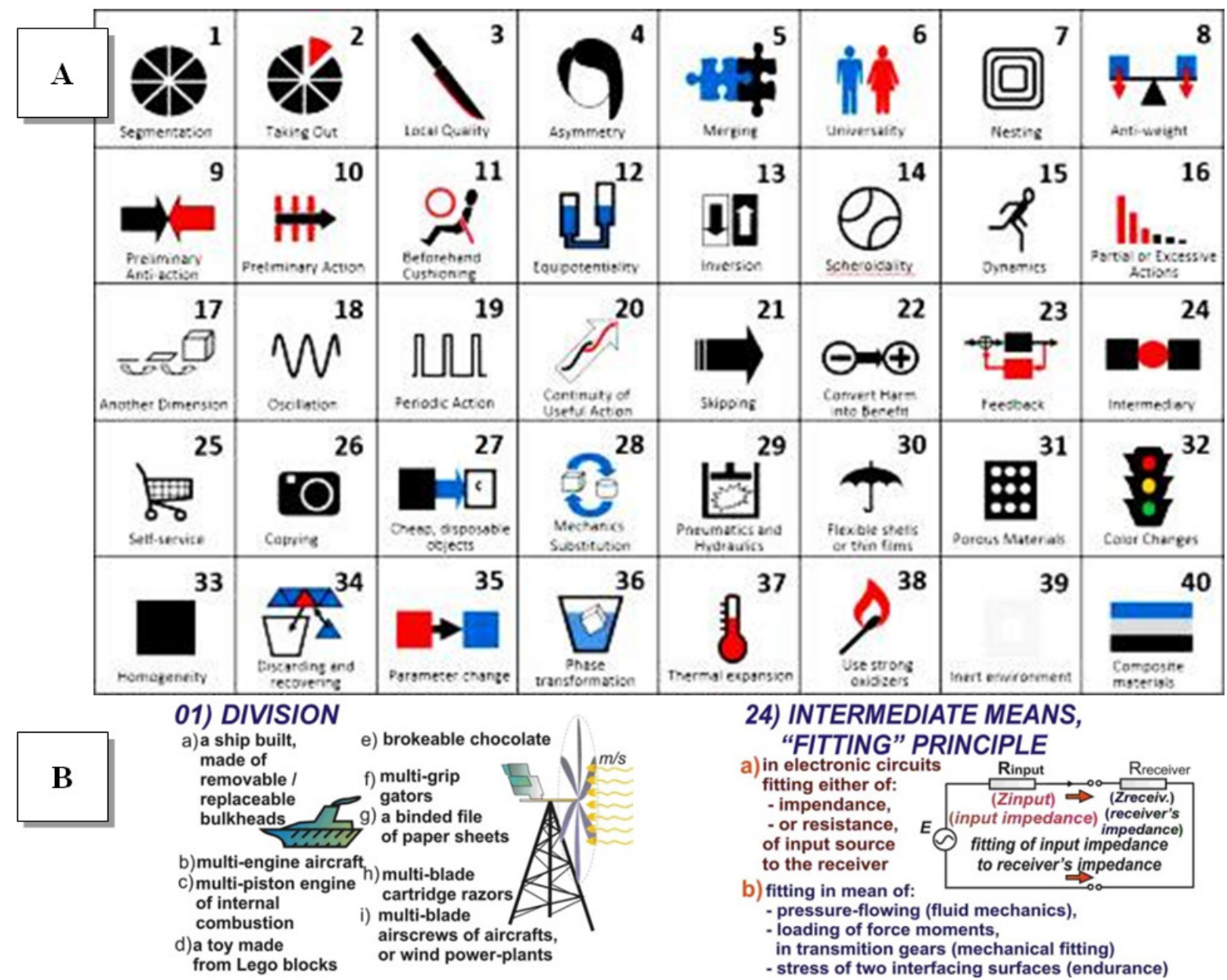

Fig. 4. TRIZ inventive principles [29] (A) and principles that guided the concept definition for the connection system, with some explanations enclosed [30] (B)

The result of the application of CE to the design of a simple component as the adapter can be seen in the evolution of this component trough the four versions illustrated in this document. To better understand this, we have underlined how the application of this methodology has provided important incremental improvements from a version to the following one.

Considering the above-listed requirements, all the versions of the adapter have a roughly-hollow cylindrical shape, i.e. with an axial symmetry. They will be made of structural steel (grade " $\mathrm{S}$ " of steels complying with the European Standard EN 10025, e.g. S355JR) and not by aluminium, thinking mainly about mechanical characteristics and weldability in any subsequent operations. Machining, cutting and welding are the manufacturing processes suitable for the fabrication of these components. 
Summary of the requirements for the adapter

\begin{tabular}{|c|c|}
\hline Requirement & Description \\
\hline $\begin{array}{l}\text { Capability of } \\
\text { transmit motion } \\
\text { (and torque up to } \\
36000 \mathrm{Nm} \text { per } \\
\text { wheel); wide } \\
\text { measuring range }\end{array}$ & $\begin{array}{l}\text { It is the fundamental aspect to be considered in such a system, since it guides } \\
\text { the static and dynamic dimensioning of the component. The operation of the } \\
\text { test installation depends on the ability to transfer a maximum torque of } \\
36000 \mathrm{Nm} \text { per wheel to the other parts of the rig. This value corresponds to the } \\
\text { torque delivered by a New Holland T5.115 tractor (maximum power of } 85 \mathrm{~kW} \text { ) } \\
\text { with the lowest gear selected, having a transmission ratio of } 1: 160 \text {. This means } \\
\text { that the system must be able to test as many tractor models as possible (about } \\
90 \% \text { of the Italian market and } 75 \% \text { of the European Market as results from } \\
\text { our database [32]), and, for each tractor, it should be capable of testing the } \\
\text { widest possible range of gears (from } 100 \% \text { to } 75 \% \text { of gear ratios). }\end{array}$ \\
\hline $\begin{array}{l}\text { Extended } \\
\text { connectivity } \\
\text { (tractor-side) } \\
\text { within the } \\
\text { indicated } \\
\text { torque/power } \\
\text { threshold } \\
(36000 \mathrm{Nm} \\
85 \mathrm{~kW})\end{array}$ & $\begin{array}{l}\text { It is necessary that the component can be fixed to a wide range of tractors } \\
\text { within the indicated torque threshold ( } 36000 \mathrm{Nm} \text {; corresponding to a } \\
\text { maximum power of } 85 \mathrm{~kW} \text {, as explained before) and, hence, that it has } \\
\text { adequate geometrical dimensions/features. As explained, the adapters must be } \\
\text { virtually compatible with all types of hub connection systems within the } \\
\text { corresponding power classes. It is worth noting that tractors more powerful } \\
\text { than } 85 \mathrm{~kW} \text { have different sizes of the wheel-to-hub connection system and, } \\
\text { therefore, cannot be physically connected to this system. Therefore, the } \\
\text { creation of proper geometrical features to the adapter warrants that the } \\
\text { connected tractor as a power and a torque complaint with the above-indicated } \\
\text { maximum torque. Moreover, possible space requirements should be } \\
\text { considered, for example, concerning the mudguard, or the need to place the } \\
\text { bolts in an accessible position for an easy assembly/disassembly. }\end{array}$ \\
\hline $\begin{array}{l}\text { Ease of alignment } \\
\text { with the other } \\
\text { components }\end{array}$ & $\begin{array}{l}\text { To avoid unforeseen stresses during the rotary motion of the component, due to } \\
\text { static and dynamic unbalances, the adapter should have some features to guide } \\
\text { its alignment to the other components with which it connects. }\end{array}$ \\
\hline $\begin{array}{l}\text { Easy-to-be- } \\
\text { manufactured } \\
\text { material }\end{array}$ & $\begin{array}{l}\text { A material is suitable for a specific application (e.g., the adapter), if it can } \\
\text { withstand the stresses when in operation, resist wear and be produced and } \\
\text { processed using common and not expensive methods. Moreover, since the } \\
\text { pieces to be manufactured are few and not mass-produced, it is necessary to } \\
\text { look for a material that does not require tricky setups and high fixed-costs, } \\
\text { since they cannot be compensated by the number of objects produced. Finally, } \\
\text { the finished component must have tight dimensional and geometric tolerances } \\
\text { and this cannot be achieved by all machining processes. }\end{array}$ \\
\hline $\begin{array}{l}\text { Estimated } \\
\text { lifespan of at least } \\
8 \text { years }\end{array}$ & $\begin{array}{l}\text { It is important to guarantee the functionality of the adapter for a time at least } \\
\text { comparable with the normal amortization period foreseen for mechanical } \\
\text { equipment for tests (i.e. } 3 \text { years according to [33]). } \\
\text { In this case, a non-continuous use of the adapter is assumed ( } 16 \text { hours per } \\
\text { month, corresponding to a full working day every two weeks); this means that, } \\
\text { if a lifespan of } 1700 \text { hours is imposed for the fatigue dimensioning, the } \\
\text { operational period is equivalent to } 8 \text { years. }\end{array}$ \\
\hline $\begin{array}{l}\text { Ease of assembly } \\
\text { and disassembly }\end{array}$ & $\begin{array}{l}\text { The component will have to be moved to test other tractors (although not very } \\
\text { frequently), so it should be relatively easy to be assembled and disassembled } \\
\text { with the equipment at disposal in the laboratory. No special technical skills } \\
\text { should be required to assembly/disassembly the adapter, and no additional tool } \\
\text { apart from a torque wrench, which allows the bolts to be tightened with a } \\
\text { predetermined torque. This aspect implies many other important advantages, } \\
\text { such as saving time, avoiding complications and errors, and preserving the } \\
\text { operators' satisfaction. }\end{array}$ \\
\hline
\end{tabular}


Table 1 (continued)

\begin{tabular}{|l|l|}
\hline Requirement & Description \\
\hline Light weight & $\begin{array}{l}\text { It is an aspect that could be grouped with the ease of assembly, but deserves a } \\
\text { category on its own due to its importance. The movements that the test rig will } \\
\text { undergo (when it has to be used or stored, or when it has to be aligned with the } \\
\text { axle of the tractor under test) will in fact be greatly facilitated by the lighter } \\
\text { and more manageable every component (including the adapter). }\end{array}$ \\
\hline $\begin{array}{l}\text { Safety in } \\
\text { handling, } \\
\text { installation, use } \\
\text { and uninstallation }\end{array}$ & $\begin{array}{l}\text { Safety requirements are essential: the adapter should be safe to handle, install, } \\
\text { use and uninstall. The achievement of these requirements is closely linked to } \\
\text { the compliance with the other requirements on the list; a trivial example } \\
\text { concerns the static design resulting from the stress analysis: if it is not carried } \\
\text { out correctly, it will lead the component to break, with serious risks for users. }\end{array}$ \\
\hline Low cost & $\begin{array}{l}\text { A limitation of costs is always glad but, in this case, it is also necessary, } \\
\text { considering that this project aims explicitly to develop a low-cost system. }\end{array}$ \\
\hline
\end{tabular}

The different versions of the adapter have been dimensioned in the following way: the initial thickness has been set equal to the thickness of existing rims used on 130-kW tractors, i.e. having a power $50 \%$ higher than the power of the biggest tractor that is intended to test. Then, features and dimensions have been iteratively optimized using FEM software, in this case Solidworks Simulation 2018. The final verification (static analysis, fatigue life) has been performed using Ansys 2019 R2 Static Structural.

\subsection{Version 1 of the hub-adapter}

The first version of the adapter is very simple and consists of three parts joined together by welding (Fig. 5), with all sharp edges bevelled: the first flange ("A"), which will be fixed to the tractor axle shaft hub, the second flange ("B"), which will be connected to the sprocket of the test rig, and a tubular spacer. The spacer has:

- an outer diameter smaller than the pitch circle diameter of the flanges to have the bolts on the outer side, which facilitates fixing;

- a height (i.e. a distance between the flanges) thought to allow the nuts to be easy tightened and to have the sprocket placed outside the tractor mudguard, not to have interferences involving the sprocket itself or the chain meshed with it (especially in small tractors);

- a cylindrical cavity that is used during assembly to collimate the adapter with the alignment hub on the axle shaft and to align also the sprocket, by inserting its hub in the spacer.

The main drawback of this version is the need for a different adapter per each class of axle shaft connection. This implies that also the pitch circle diameter of the flange B cannot be standardized and, consequently, many circular series of holes should be created on the sprocket (NB: as this could not be possible for all diameters, it is also necessary to have at disposal many versions of the sprocket). In addition to this, with smaller wheels the tubular would not be large enough to be used to align the hub. The last problem is due to the space between the alignment cylinder and the fixing bolts, too small to allow having the proper thickness of the tubular to transmit safely the stresses.

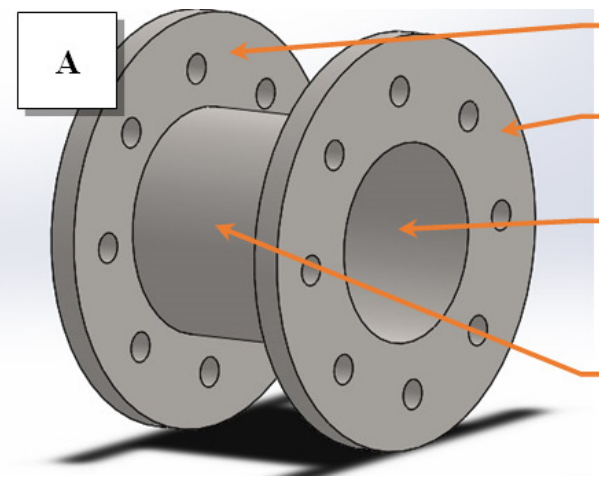

Fig. 5. Version 1 of the adapter:
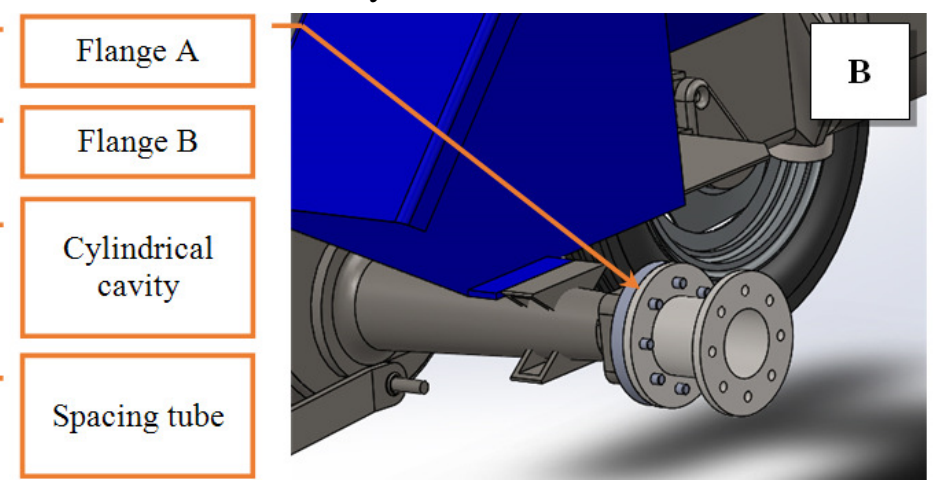

$$
\text { installation on a tractor }
$$




\subsection{Version 2 of the hub-adapter}

This version can exhibit significant changes with respect to the first version (Fig. 6). The most important is the widening of the spacer diameter, which now lies outside the pitch circle diameter of the bolts of the tractor axle shaft. Consequently, the flange B has also been enlarged and is now more external than the spacer (it is shaped like a rim). The principle that has guided these choices is having a greater universality at least from the side of the sprocket, so that all adapters can interface with the same sprocket (because the pitch circle diameter of the fixing holes on the sprocket is unique). When there is the need to connect the test rig to tractors with different classes of rims, there is the need to use an adapter with a different pitch circle diameter on the side of the tractor, but it is possible to use the same sprockets (Fig. 6.C and D). Other design features are:

- the diameters of flanges $\mathrm{A}$ and $\mathrm{B}$ exceed the tube diameter for easy creation of the weld beads outside the spacer, the internal cavity is wide enough to perform the internal welds; also the increased tube diameter implies longer weld beads, so the component can withstand higher stresses;

- the bell-like shape allows, as in version 1, to distance the sprocket from the axle shaft terminal, which is very useful in small tractors where there could be not enough room to assemble the adapter-sprocket system under the mudguard.

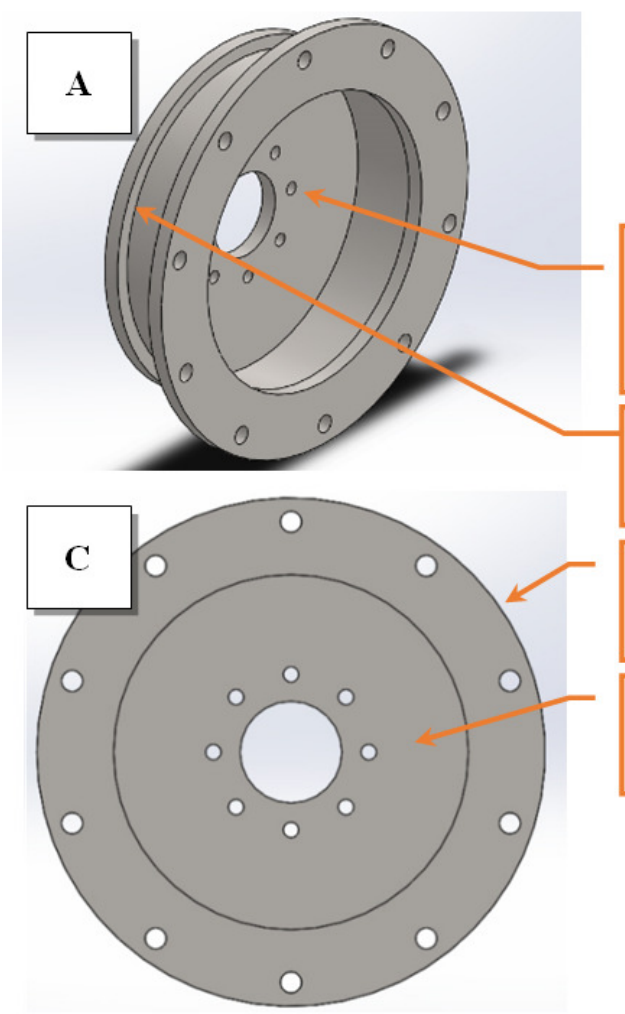

\section{"Internal" position of axle shaft pitch circle diameter \\ Exceeding edges for welding}

Flange B standard geometry

Flange A variable geometry


Fig. 6. Version 2 of the adapter: A - 3D drawing with the parts in evidence; B - example of installation on a tractor; $\mathrm{C}$ and $\mathrm{D}$ - example of two adapters for different rim classes

The drawbacks of this version are:

- the weight, which is greater than in the previous version (45 kg vs. $35 \mathrm{~kg}$ );

- some production difficulties (as evidenced by a possible supplier) about the internal welds; the complication could arise from the difficulty to keep the optimal angle of the electrode during welding, with possible weakening of the maximum strength and reduction of the fatigue life of the component (subjected to rotating bending of considerable intensity, equal to $12000 \mathrm{Nm}$ ); moreover, once the component has been welded, it must be rectified using proper machines, which further increases the production time and costs. 


\subsection{Version 3 of the hub-adapter}

The changes introduced in the third version are largely due to the discussions had with possible manufacturers who, based on their experience, have offered useful suggestions to improve the product. The major modification was to remove the welds and design an adapter that can be obtained by turning from a single block of steel. By doing so, it is possible to obtain directly a finished piece, without further machining processes requiring realignments, and it allows also creating fillets that avoid dangerous concentrations of stress (Fig. 7). This integral design is also recommended by the DFMA guidelines, which suggest always to limit the number of components to reduce the time and costs during the manufacturing and assembly phases. The negative aspects of this version are: its weight, still high $(33 \mathrm{~kg}$ ), and the cost, also high, which is around 800.00 EUR per piece (according to quotations).

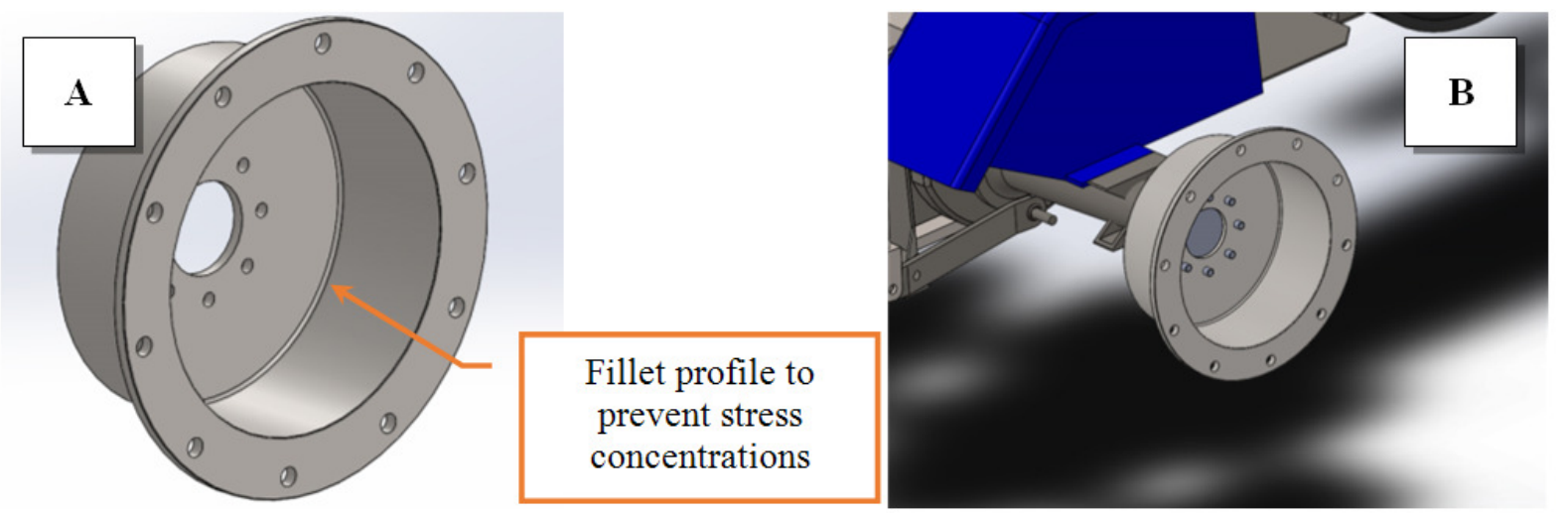

Fig. 7. Version 3 of the adapter: A - 3D drawing; B - example of installation on a tractor

\subsection{Version 4 of the wheel adapter}

This version has undergone the biggest changes, compared to the previous three versions, with incomparable advantages, explained hereinafter. The changes were only possible in conjunction with changes in the test rig general layout (Fig. 8): thanks to the use of a turnbuckle per tractor side (used to measure the chain tension and, hence, the tractor torque), the transmission chains meshing with the sprockets will show a concave path, thus avoiding possible interferences with the tractor mudguards. Instead, the possible interferences due to the dimensions of the sprocket are quite limited: according to our database, a sprocket would interfere with the mudguard only in a small percentage of small-size tractors (only $30 \%$ of tractors under $30 \mathrm{~kW}$ ). Therefore, in the majority of cases (about $90 \%$ of tractors of all sizes), being solved the interference of the chains, it is no longer necessary for the adapter to keep the sprocket external to the mudguard: the sprocket can be positioned exactly in place of the wheel and the spacer, present in the previous versions of the adapter, can be eliminated. This is in accordance also with principle 17 of the TRIZ table of inventive principles, namely "Another dimension": according to this principle, the component has been simplified by changing its mainly-3D conformation to a 2D configuration.



Fig. 8. Change in the test rig layout which leads to simplification of the adapter:

A - original layout; B - improved layout (with a chain turnbuckle)

Hence, the adapter shape has been reduced to a disc with two sets of holes, lying on different pitch circumferences. The innermost holes are used to fix the adapter to the axle shaft bolts and their 
position varies according to the class of the rim. The outermost ones have a standardized layout and are used to connect the adapter to a so-called "A-type sprocket" (i.e. a flat sprocket plate-wheel with no hubs that extrude on either side) with a central bore (to be created through plasma or laser cutting; see Fig. 9). According to the DFA principles, the adapter has been provided also with two additional holes, useful to accommodate two pins acting as aligners during the assembly (Fig. 9.A). Compared to the previous versions (Table 2), there is also an inversion of the assembly sequence: it is advisable, in this case, that the adapter is firstly fixed to the sprocket, and then this assembly is fixed on the axle shaft instead of the rim.

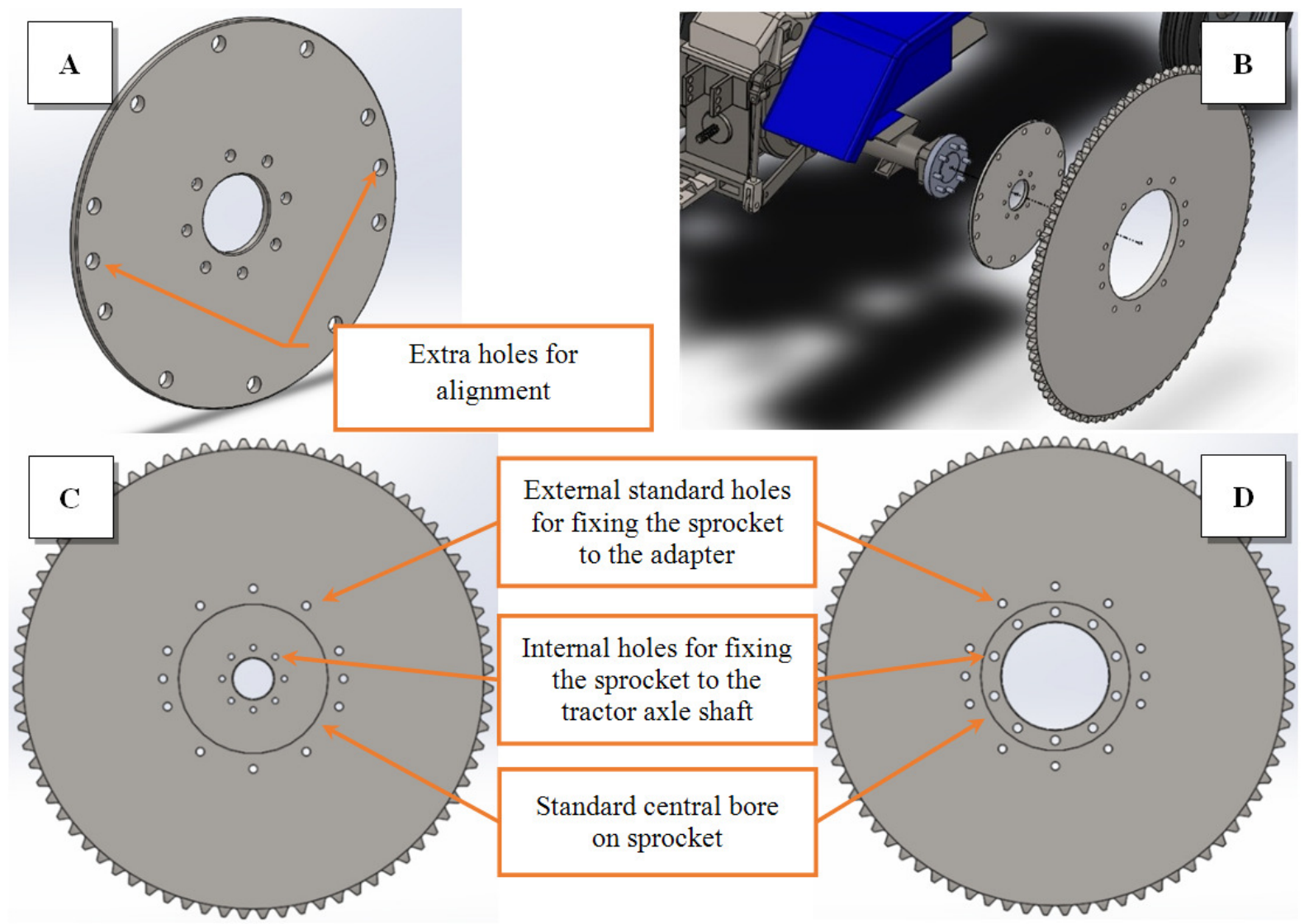

Fig. 9. Version 2 of the adapter: A - 3D drawing; B - example of installation on a tractor; $\mathrm{C}$ and $\mathrm{D}$ - example of two adapters for different rim classes (NB: the sprocket is the same)

Table 2

Pros and cons of each version of the adapter (percentage variations of mass and cost refer to the previous version; "V" stands for "version number")

\begin{tabular}{|c|c|c|c|c|}
\hline \multirow{2}{*}{$\begin{array}{l}\text { Version } \\
\text { Image }\end{array}$} & 1 & 2 & 3 & 4 \\
\hline & & & & \\
\hline $\begin{array}{l}\text { Technical } \\
\text { specs. }\end{array}$ & $\begin{array}{l}\text { Geometric } \\
\text { dimensions } \\
\text { depending on rim } \\
\text { classes }\end{array}$ & $\begin{array}{l}\text { Standardized } \\
\text { geometry for spacer } \\
\text { and flange "B" }\end{array}$ & $\begin{array}{l}\text { Standardized } \\
\text { geometry for spacer } \\
\text { and flange "B" }\end{array}$ & 2D(flat) layout \\
\hline Max dim.: & $\emptyset 400 \times 180 \mathrm{~mm}$ & $\varnothing 520 \times 180 \mathrm{~mm}$ & $\varnothing 520 \times 180 \mathrm{~mm}$ & Ø $520 \times 15 \mathrm{~mm}$ \\
\hline
\end{tabular}


Table 3 (continued)

\begin{tabular}{|c|c|c|c|c|}
\hline \begin{tabular}{|l|} 
Flange \\
thickness:
\end{tabular} & $20 \mathrm{~mm}$ & $20 \mathrm{~mm}$ & $15 \mathrm{~mm}$ & $15 \mathrm{~mm}$ \\
\hline Spacer tck.: & $10 \mathrm{~mm}$ & $7 \mathrm{~mm}$ & $7 \mathrm{~mm}$ & - \\
\hline Max mass: & $35 \mathrm{~kg}$ & $45 \mathrm{~kg} \quad(+28 . \%)$ & $33 \mathrm{~kg} \quad(-26.7 \%)$ & $23 \mathrm{~kg} \quad(-30.3 \%)$ \\
\hline Est. cost: & 800 EUR & 800 EUR $\quad(+0.0 \%)$ & 700 EUR $\quad(-12.5 \%)$ & 350 EUR $(-50.0 \%)$ \\
\hline Pros & $\begin{array}{l}\text { Compact design } \\
\text { Easy access to the } \\
\text { fixing bolts }\end{array}$ & $\begin{array}{l}\text { Standardization of } \\
\text { components } \\
\text { Standardization of the } \\
\text { pitch circle diameter } \\
\text { (flange B) } \\
\text { Adequate space for } \\
\text { dimensioning the } \\
\text { spacer thickness }\end{array}$ & $\begin{array}{l}\text { Standardization of } \\
\text { some parts } \\
\text { Standardization of the } \\
\text { pitch circle diameter } \\
\text { (flange B) } \\
\text { Adequate space for } \\
\text { dimensioning the } \\
\text { spacer thickness } \\
\text { Easy manufacturing } \\
\text { processes (turning) }\end{array}$ & $\begin{array}{l}\text { Standardization of } \\
\text { the pitch circle } \\
\text { diameter (flange B) } \\
\text { Simple } \\
\text { manufacturing } \\
\text { process } \\
\text { Light weight } \\
\text { Low costs } \\
\text { Low stress and } \\
\text { fatigue phenomenon }\end{array}$ \\
\hline Cons & $\begin{array}{l}\text { Possible difficulties in } \\
\text { manufacturing } \\
\text { Adequate spacer } \\
\text { thickness impossible } \\
\text { due to geometric } \\
\text { constraints } \\
\text { Flange B pitch circle } \\
\text { diameter impossible to } \\
\text { standardize } \\
\text { Possible problems with } \\
\text { the sprocket hub } \\
\text { centring }\end{array}$ & $\begin{array}{l}\text { Possible welding } \\
\text { difficulties } \\
\text { Time-consuming } \\
\text { manufacturing } \\
\text { Excessive weight } \\
\text { Very high costs }\end{array}$ & $\begin{array}{l}\text { Quite high costs (it is } \\
\text { created from a solid } \\
\text { block of metal) } \\
\text { High weight }\end{array}$ & $\begin{array}{l}\text { Not usable for some } \\
\text { small tractors } \\
\text { (however a limited } \\
\text { percentage of the } \\
\text { market) }\end{array}$ \\
\hline
\end{tabular}

From the point of view of the component static dimensioning, this flat-disc shape of the last version of the adapter has the advantage that does not undergo any rotating bending stresses, causing mechanical fatigue problems. Indeed, the force exerted by the chain is very close to the adapter fixing plane on the axle shaft. Other benefits of this version are:

- the component has a very simple shape that can be obtained from a piece of sheet metal, e.g. by plasma cutting, with very little scrap; thanks to the fewer complications, the manufacturing time is reduced;

- the disc resulting from the central bore can be used to build another component used in the same test rig;

- the weight of the adapter is much lower than in the previous versions (23 $\mathrm{kg}$ compared to $45 \mathrm{~kg}$ of version 2), leading to easier assembly operations;

- given the points above, there is a cost saving of $50 \%$ with respect to the previous versions (estimation made by a possible manufacturer).

\section{Conclusions}

The here-illustrated case-study, i.e. an adapter to connect the rear axle shafts of a tractor to a test rig, shows how the Concurrent Engineering principles, together with TRIZ tools and some computeraided programs, have led to develop a product that is optimised by the point of view of the design and assembly. Indeed, after illustrating the whole progressive development process, the final version of the so-developed component is presented. It can simultaneously satisfy a series of requirements made explicit in the design phase: easy manufacturability (it requires only common machine tools: lathe, laser or plasma cutting machine, milling machine), easy assemblability (thanks to the presence of alignment features), common material (S355JR EN 10025 structural steel), compactness (diameter $520 \mathrm{~mm}$, thickness $15 \mathrm{~mm})$, lightweight $(23 \mathrm{~kg}$, i.e. $12 \mathrm{~kg}$ less than the very first version of this component), safety in its handling and use (the alignment feature holds the component in place while it is bolted), low cost (about 350 EUR, according to our estimates, i.e. 450 EUR less than in the first 
version). The design methods used for the development of the final design of this component were also applied to the design of the entire test rig for tractors, of which this component is part. This allowed defining at a project with a relatively-low budget (about 30000 EUR) and a relatively-simple layout, made up of only 3 main subassemblies. That notwithstanding, the range of testable tractor models and performance is very wide: our estimates indicate that the testable models are about $90 \%$ of those on the Italian market, i.e. essentially all tractors under $100 \mathrm{~kW}$ of maximum power.

\section{Acknowledgements}

This research was developed within the "BIO-TRACT-EFFICIENCY" ("Experimental investigation on the efficiency of agricultural machines powered with different fuels") internal research project, grant number TN200F. Moreover, the authors wish to thank the staff of the "Consorzio Agrario di Bolzano" (the "Farmers' cooperative of Bolzano", Italy; www.ca.bz.it/) and Dr. Franco Concli for the useful suggestions that allowed us to further improve the design of the adapter, the object of this study.

\section{References}

[1] Bacenetti J., Lovarelli D., Facchinetti D., Pessina D. An Environmental Comparison of Techniques to Reduce Pollutants Emissions Related to Agricultural Tractors, Biosyst. Eng.,vol. 171, 2018, pp. 30-40.

[2] Gonzalez-de-Soto M., Emmi L., Benavides C., Garcia I., Gonzalez-de-Santos P. Reducing Air Pollution with Hybrid-Powered Robotic Tractors for Precision Agriculture, Biosyst. Eng., vol. 143, 2016, pp. 79-94.

[3] Renzi M., Bietresato M., Mazzetto F. An Experimental Evaluation of the Performance of a SI Internal Combustion Engine for Agricultural Purposes Fuelled with Different Bioethanol Blends, Energy, vol. 115, 2016, pp. 1069-1080.

[4] Froment Dynamometers, Froment and Co. Ltd Stanford, UK

[5] Froment Dynamometers, Froment SIGMA 50 Dynamometers, 2018, Froment and Co. Ltd Stanford, UK

[6] Bietresato M., Malavasi M., Mazzetto F. Set-up of Integrated System for Real-Time Detection and Recording of Many Engine Parameters of Agricultural Machines during Dyno Tests. Proceedings of the 18th International Scientific Conference"Engineering for Rural Development", 2019, Jelgava Latvia, pp. 160-173.

[7] Bietresato M., Mazzetto F. Ideation, Realization and Experimentation of Prototype Device for Measuring Farm Tractor Fuel Consumption during Dyno Tests, Engineering for Rural Development,2018, Jelgava Latvia, pp. 362-372.

[8] Bietresato M., Caligiuri C., Bolla A., Renzi M., Mazzetto F. Proposal of a Predictive Mixed Experimental- Numerical Approach for Assessing the Performance of Farm Tractor Engines Fuelled with Diesel- Biodiesel-Bioethanol Blends, Energies, vol. 12, 2019, p. 2287.

[9] Bietresato M., Friso D. Durability Test on an Agricultural Tractor Engine Fuelled with Pure Biodiesel (B100), Turkish J. Agric. For., vol. 38, 2014

[10] Bietresato M., Caligiuri C., Renzi M., Mazzetto F. Use of Diesel-Biodiesel-Bioethanol Blends in Farm Tractors: First Results Obtained with a Mixed Experimental-Numerical Approach, Energy Procedia, vol. 158, 2019, pp. 965-971.

[11] Lowenstein A., Schlosser S., and Winter G. Concurrent Engineering, Dig. Pap. - Int. Test Conf., 1990, pp. 258-259.

[12] Josip Stjepandić N. W. Concurrent Engineering in the 21st Century, Springer International Publishing, Cham, 2015.

[13] Benmoussa R., Guio R., De Dubois S., Koziołek S. Innovation Breakthroughs for Developing Countries 2019.

[14] Bietresato M., Analisi e Riprogettazione Di Antenne Paraboliche per La Ricezione Satellitare Tramite Metodologie Integrate Di Concurrent Engineering [Analysis and Re-Design of Satellite Parabolic Antennas through Integrated Methodologies of Concurrent Engineering], 2002, Università degli Studi di Padova - University of Padova.

[15] Bietresato M., Guarnieri A., Rondelli V., Weger J., Mazzetto F., Concept and Design of the 
ROPS for a Small Articulated Tractor for Extreme Sloped Vineyards, Proceedings of the International Conference of Agricultural Engineering, 2014, Zurich, Switzerland, pp. 1-8.

[16] Mitzner K., Introduction to Design for Manufacturing, Complet. PCB Des. Using OrCad Capture Layout, 2007, pp. 79-107.

[17] Molloy O., Tilley S., Warman E. Design for Manufacturing and Assembly, Springer US, 1998, Boston, MA.

[18] Altshuller G. S. Creativity as an Exact Science: The Theory of the Solution of Inventive Problems, New York, Gordon and Breach, 1988.

[19] Index [online][11.02.2020] Available at: www.opensourcetriz.com.

[20] Chechurin L., Borgianni Y. Understanding TRIZ through the Review of Top Cited Publications Comput. Ind., vol. 82, 2016, pp. 119-134.

[21] Boothroyd G., Dewhurst P., Knight W. Product Deisgn for Manufacture and Assembly, New York: CRC Press, 2011, pp. 710.

[22] Dassault Systèmes, 2020, 3D Design \& Engineering Software - Dassault Systèmes.

[23] Ansys, 2020, Ansys: Engineering Simulation \& 3D Design Software.

[24] ETRTO - European Tyre and Rim Technical Organisation, Standards Manual, 2020, Brussels, Belgium.

[25] ISO 5711:1995(E). Tractors and machinery for agriculture and forestry - Whhel to hub fixing dimensions. International-Standard-Organization, 1995.

[26] Bartolozzi F., Trattori Europei Sprofondo Rosso, Macch. e Mot. Agric., 2019, pp. 4-10.

[27] Con T., Immatricolazioni-Registrations Gennaio/January-Dicembre/December 2019,” (December), 2019.

[28] TRIZ_GB [online][11.02.2020] Available at: www.triz40.com.

[29] Pelkonen T., List of Triz Inventive Principles.

[30] Wikipedia, 2020, "TRIZ."

[31] Stjepandić J., Rock G., Bil C. Concurrent Engineering Approaches for Sustainable Product Development in a Multi-Disciplinary Environment, Springer London, London, 2013.

[32] European Agricultural Machinery Industry Association, Stable Year for Tractor Registrations in 2019, CEMA office for statistics, 2020.

[33] Ministero delle finanze, Tabella Dei Coefficienti Di Ammortamento DM 31/12/1988. 1988, 